\title{
LAS HERENCIAS DE KANT Y DE GOETHE EN EL PENSAMIENTO DE MAX WEBER *
}

José M. ${ }^{a}$ González García

Instituto de Filosofía, CSIC, Madrid

RESUMEN. El presente artículo parte de dos bipótesis de trabajo para la interpretación de la sociología de Max Weber. La primera toma su punto de apoyo en la filosofía y afirma que sólo podemos entender correctamente a Weber si lo leemos con el trasfondo de la filosofía de Kant. La segunda se apoya en la literatura y sostiene que gran parte de los elementos teóricos que configuran los hallazgos fundamentales de la sociología weberiana son variaciones sobre temas de Goethe. Tanto la lectura de Weber en clave kantiana como la lectura goethiana pueden arrojar nuevas luces sobre la interpretación del fundador de la sociología comprensiva.

Quiero partir de dos hipótesis de trabajo para la interpretación de la sociología de Max Weber. La primera toma su punto de apoyo en la filosofía y afirma que sólo podemos entender correctamente a Weber si lo leemos con el trasfondo de la filosofía de Kant. La segunda se apoya en la literatura y sostiene que gran parte de los elementos teóricos que configuran los hallazgos fundamentales de la sociología weberiana son variaciones sobre temas de Goethe. Tanto la lectura de Weber en clave kantiana como la lectura goethiana pueden arrojar nuevas luces sobre la interpretación del fundador de la sociología comprensiva.

Creo que es plausible mantener que en el «núcleo teórico duro» de los

* Una primera versión de este artículo ha sido presentada en el Instituto de Filosofía, en el Seminario celebrado con ocasión del Bicentenario de la Crítica de la Razón práctica. 
sociólogos clásicos encontramos una filosofía y sólo desde la recepción, transformación e, incluso, inversión de dicha filosofía es posible entender su obra. Así, detrás de Marx encontramos la filosofía de Hegel y, tras Weber, Simmel e incluso Durkheim, la de Kant. Desde luego que las relaciones no son siempre fáciles, sino más bien bastante problemáticas. E1 caso de Marx es bien conocido: ya casi al final de su vida se declara abiertamente discípulo de Hegel, reivindica su figura frente a los «gruñones, petulantes y mediocres epígonos que dictan hoy cátedra en la Alemania culta» y que arremeten contra el maestro tratándolo como a «perro muerto». Y afirma: «El hecho de que la dialéctica sufra en manos de Hegel una mistificación, no obsta para que este filósofo fuese el primero que supo exponer de un modo amplio y consciente sus formas generales de movimiento. Lo que ocurre es que la dialéctica aparece en él invertida, puesta de cabeza. No hay más que darle la vuelta, mejor dicho ponerla de pie, y enseguida se descubre bajo la corteza mística la semilla racional» ${ }^{1}$.

A pesar de estas palabras de Marx, resulta bastante evidente que sus relaciones teóricas con Hegel son más complejas que las sugeridas por la imagen de la inversión, del poner de pie lo que se hallaba cabeza abajo. En el caso que aquí nos ocupa, la herencia de Kant en el pensamiento de Weber es también compleja: quisiera afirmar, de entrada, que hay continuidades, discontinuidades, rupturas, inversiones y, por expresarlo en clave goethiana, «afinidades electivas». Desde luego, no se puede decir que Weber sea un kantiano, ni un neokantiano, pero tal vez sí pueda afirmarse que desarrolla una sociología de cuño kantianizante. En muchos de sus escritos rezuman planteamientos kantianos, transformados jurídica, histórica o sociológicamente, pero el núcleo del pensamiento permanece. Después de la transformación queda algo así como un «aire de familia» que emparenta a Weber con la filosofía kantiana. Quisiera mantener también la hipótesis o, mejor dicho, la sospecha de que el neokantismo del suroeste de Alemania juega un papel de intermediario en las relaciones Kant-Weber similar al jugado por Feuerbach en las relaciones entre Hegel y Marx. Si bien una parte importante del programa de investigación de Weber, y básicamente su metodología, se constituye en un diálogo crítico con Windelband, Lask y, especialmente, con Rickert, éstos no pueden sustituir una lectura directa de los textos de Kant, lectura que Weber realiza ya en sus años de estudiante en Heidelberg, donde asiste además a las clases de Kuno Fischer. Además, en el campo de la sociología política y de la teoría del Estado no hay que olvidar la influencia ejercida por Jellinek, maestro y compañero de Weber en la Universidad de Heidelberg, y representante ilustre del neokantismo en la filosofía del derecho y del Estado 2.

${ }^{1}$ K. Marx, Postfacio a la $2 .^{a}$ ed. del primer volumen de El Capital. Cito por la traducción de W. Roces, México, FCE, 1973 (8." reimp. de la 2." ed.), p. XXIV.

2 De la ya larga bibliografía sobre el trasfondo neokantiano de la obra de Max Weber 
Por otra parte, me parece obvio recordar que la filosofía de Kant no es la única fuente de la metodología weberiana. Su programa de investigación se constituye en enfrentamiento crítico con Marx y con las versiones vulgares del materialismo dialéctico, con las teorías de sus maestros Roscher y Knies, representantes de la escuela histórica alemana de economía, y con la escuela marginalista austríaca. $\mathrm{Y}$, aunque en algunas expresiones y planteamientos resuenen ecos de Nietzsche, las soluciones que Weber aporta son radicalmente contrarias. Desde mi punto de vista, no puede mantenerse el intento de W. Hennis de releer de nuevo a Weber a la luz de Nietzsche ${ }^{3}$. Pero no es éste el lugar apropiado para entrar más detalladamente a analizar las complejas relaciones de Weber con Marx o con Nietzsche.

Siguiendo el análisis de W. Schluchter, podemos afirmar que Weber se rebela contra el monismo naturalista que bloquea una nueva libertad al pensamiento y a la vida. «Por ello — afirma Schluchter- la vuelta al criticismo de Kant supone un acto de liberación, especialmente cuando esta vuelta, como

y, especialmente, sobre sus relaciones con Heinrich Rickert destacan las siguientes obras: H. H. Bruun, Science, Values and Politics in Max Weber's Metbodology, Copenhaguen, Munskgaard, 1972; D. Henrich, Die Einheit der Wissenschaftslebre Max Webers, Tübingen, Mohr, 1952; F. Loos, Zur Wert - und Rechtslebre Max Webers, Tübingen, Mohr, 1970; R. PREwo, Max Webers Wissenschattsprogramm, Frankfurt, Suhrkamp, 1979; W. SCHLuchter, Die Entwicklung des okzidentalen Rationalismus, Tübingen, Mohr, 1979. Aunque casi todos los estudios se centran en la influencia de Rickert en Weber, también habría que analizar la influencia contraria, la de Weber en Rickert, reconocida por éste en su artículo «Max Weber und seine Stellung zur Wissenschaft», en Logos, vol. XV, 1926, pp. 222-237. En segundo lugar, aunque se suele reconocer la influencia de Emil Lask sobre Weber, especialmente en la transmisión de la obra de Fichte a través de su disertación (Fichtes Idealismus und die Geschichte), falta una monografía sobre dicha influencia. Algunos elementos, referidos especialmente a la teoría del derecho, pueden verse en la obra de Loos citada más arriba. Por último, sobre Georg Jellinek y Max Weber puede verse el libro de R. BENDIx y G. Roth, Scholarship and Partisansbip. Essays on Max Weber, Berkeley, 1971.

${ }^{3}$ Cfr. W. Hennis, Max Webers Fragestellung, Tübingen, Mohr, 1987, especialmente el cap. 4: «Die Spuren Nietzsches im Werk Max Webers». Esta obra ha removido de nuevo la polémica sobre las relaciones entre Nietzsche y Weber. En la amplia bibliografía sobre estas relaciones destacan los siguientes libros y artículos: E. FLEISCHMANN, «De Weber à Nietzsche», en Archives Europ. Sociologiques, 5 (1964), pp. 190-238; W. Mom mSEN, «Universalgeschichtliches und politisches Denken bei Max Weber», en Historische Zeitscbrift, vol. 201 (1965), pp. 557-612, y recogido en la obra del mismo autor, Max Weber: Gesellschaft, Politik und Gescbicbte, Frankfurt, Suhrkamp, 1974 (hay trad. cast. en la Edit. Alfa); D. J. K. PeukerT, «Die "letzten Menschen”. Beobachtungen zur Kulturkritik im Geschichtsbild Max Webers», en Geschichte und Gesellschaft, 12 (1986), pp. 425-442; H. BAIER, «Die Gesellschaft. Ein langer Schatten des toten Gottes. Friedrich Nietzsche und die Entstehung der Soziologie aus der Geist der Décadence», en Nietzsche Studien, vols. 10-11 (1981-82), pp. 6-33; R. EDEN, Political leadership and Nibilismus. A Study of Weber and Nietzsche, Tampa, University Press of Florida, 1984; R. EdEN, «Bad Cons cience for a Nietzschean Age: Weber's Calling for Science», en Rev. Polit. USA, 45, núm. 3 (1983), pp. 366-392; B. S. Turner, «Nietzsche, Weber and the devaluation of politics: the problem of state legitimacy", en The Sociological Revue, 30 (1982), pp. $367-$ 391; G. Stauth y B. S. Turner, «Nietzsche in Weber oder die Geburt des modernen Genius im profesionellem Menschen», en Zeitschift für Soziologie, 15, núm. 2 (1986), pp. 81-94. 
en Rickert, se modifica con una forma de viraje axiológico y está ligada a un rechazo de la pretensión monopolizadora de las ciencias naturales» ${ }^{4}$.

Esta vuelta a Kant supone, entre otras cosas, una vuelta a la concepción del individuo como ser radicalmente racional. Y Weber desarrolla esta idea en su exigencia de que el individuo llegue a convertirse en persona mediante una elección libre de los valores que han de articular su existencia como «hombre de cultura» y posibilitar una dirección consciente de su propia vida. Sólo a través de una elección responsable y libre de los valores últimos que dan sentido a la vida, de un control racional y consciente sobre sí mismo y de la honestidad intelectual se puede llegar a ser persona. Y esto es particularmente cierto en una situación social y política marcada por la desaparición dẹl individuo y su subordinación a instituciones sociales como los partidos de masas, la maquinaria burocrática, el trabajo anónimo y anonimizante en la gran fábrica o la maquinaria de exterminio del ejército.

Desde este punto de vista, Weber no puede admitir el planteamiento científico de Marx, según el cual el individuo es considerado como una mera «personificación de categorías económicas», como un mero «representante de intereses y relaciones de clase». "Quien como yo - afirma Marx- concibe el desarrollo de la formación económica de la sociedad como un proceso bistórico-natural, no puede hacer al individuo responsable de relaciones de que él es solamente criatura, aunque subjetivamente se considere muy por encima de ellas» ${ }^{5}$.

Contra esta visión objetivista de la ciencia y del individuo reacciona Weber con el intento de crear una ciencia comprensiva que dé cuenta de la acción social de los individuos y del sentido que dichos individuos dan a su acción. Desde este rechazo hay que entender el individualismo - no sólo metodológico- de Weber. Y frente al monismo naturalista que concibe a la sociedad como un proceso histórico-natural, Weber desenterrará el hacha de guerra del dualismo, o de los dualismos. Ásí, pues, su mentor filosófico no podrá ser nunca Hegel, sino Kant. No hay reconciliación posible de opuestos, sino que las paradojas y contradicciones se mantienen y se llevan hasta el final.

Desde este punto de vista cabría leer la La ética protestante como el intento de desentrañar una de las características de la modernidad, la del deber profesional como una interpretación del imperativo categórico kantiano que provee al individuo de la carga motivacional necesaria para desarrollar el llamado «espíritu del capitalismo». Este no se basaría en un mero cálculo de utilidades como propondría la escuela de economía nacional, ni sería un mero reflejo superestructural en la conciencia de los individuos, como querrían hacer ver las interpretaciones marxistas, sino que descansaría en la percep-

${ }^{4}$ W. SCHLuch ter, Religion und Lebensfübrung, de próxima aparición en Suhrkamp. Cito por el manuscrito al que he tenido acceso gracias a la amabilidad del profesor Schluchter (p. 45).

${ }^{5}$ K. MARX, op. cit., p. XV. 
ción básica de un deber incondicionado que daría sentido a la actividad incesante y al trabajo del hombre.

Precisamente en este aspecto enlazaría con la otra hipótesis fundamental de mi interpretación: la bipótesis literaria que querría ver en la influencia de Goethe una de las claves fundamentales de la obra de Weber. Si, por un lado, la sociología clásica sólo se puede entender desde sus raíces filosóficas, por otro, todavía se encuentra en una ligazón muy fuerte con la literatura, ligazón que irá perdiendo progresivamente en un proceso que Wolf Lepenies denomina «desliteraturización» (Entliterarisierung): «desde la mitad del siglo xvirr se deja observar un proceso, que describo como "desliteraturización". Entiendo por tal la separación respecto a las ciencias de tradiciones y programas teóricos que serán descalificados como literarios y por tanto acientífico" ${ }^{6}$. Aunque en el momento en que Weber escribe su obra el proceso de separación de literatura y sociología ha avanzado mucho, todavía quedan en él bastantes referencias a la literatura clásica alemana y, especialmente, al Goethe maduro. A mi juicio, estas referencias literarias no son meros adornos, sino que reflejan las tomas de postura personal del propio Weber dentro de un discurso sociológico que tiene pretensiones de cientificidad y de ausencia de juicios de valor.

Esto me parece especialmente válido para la interpretación de La ética protestante, donde Goethe aparece de una manera explícita en los puntos fundamentales de la argumentación. Así, por ejemplo, al intentar explicar las relaciones entre conocimiento y realidad social, Weber utiliza el concepto de "afinidades electivas», traduciendo sociológicamente la idea que Goethe había tomado prestada de la química de su tiempo para dar título y trama argumental a una de sus novelas ?

6 W. LePENIES, «Ueber den Krieg der Wissenschaften und die Literatur. Der Status der Soziologie seit der Aufklärung», en Merkur, 40 Jg., Heft 6, junio 1986, p. 482. Un estudio más detallado de las relaciones entre sociología y literatura en Francia, Inglaterra y Alemania puede verse en el espléndido libro, del mismo autor, Die drei Kulturen. Soziologie zwischen Literatur und Wissenschaft, Munich, Hanser, 1985.

7 Retomo aquí algunas reflexiones de $\mathrm{mi}$ artículo «Afinidades electivas entre sociología y literatura», publicado en Estudios, 11 (1987), pp. 41-51. Sobre el tema de las afinidades electivas en Weber pueden verse también los artículos de R. H. HowE, «Max Weber's Elective Affinities: Sociology within the Bounds of Pure Reason», en $A J S$, vol. 84/2 (1978), pp. 366-385, y de S. A. Kent, "Weber, Goethe and the Nietzschean Allusion: Capturing the Source of the "Iron cage" Metaphor", en Sociological Analysis, $44 / 4$ (1983), pp. 297-320, y de J. J. R. Thomas, "Ideology and Electiv Affinity», en Sociology, 19/1 (1985), pp. 39-54. Debo esta última referencia a Salvador Giner, quien en Ensayos Civiles (Barcelona, Península, 1987) se ocupa tangencialmente de las dificultades que el uso de la noción goethiana de afinidad electiva tiene en Max Weber. Por otro lado, cabe recordar que el interés de Max Weber por Goethe comienza ya en la adolescencia cuando, para huir del aburrimiento de las clases en el Gimnasium, «leyó de cabo a rabo y en secreto una edición en cuarenta volúmenes de Goethe en su propio pupitre» (A. Mitzman, La jaula de bierro. Una interpretación bistórica de Max Weber, Madrid, Alianza, 1969, p. 31). Sobre la influencia de Goethe y Kant en el joven Weber puede verse, también, la biografía escrita por Marianne WEBER, Max Weber. Ein Lebensbild, Tübingen, Mohr, 1984 (3..$^{\mathrm{ed}}$.). 
También en las últimas páginas de La ética protestante, donde Weber expone de una manera más clara su propia postura personal, aparece de nuevo Goethe:

«A decir verdad, la idea de que el trabajo profesional moderno posee carácter ascético no es nueva. Es lo mismo que quiso enseñarnos Goethe desde la cima de su profundo conocimiento de la vida, en los Wanderjabren y en la conclusión del Fausto, a saber: que la limitación al trabajo profesional, con la consiguiente renuncia a la universalidad fáustica de lo humano, es una condición del obrar valioso en el mundo actual, y que, por tanto, la "acción" y la "renuncia" se condicionan recíprocamente de modo inexorable; y esto no es otra cosa que el motivo radicalmente ascético del estilo de vida del burgués (supuesto que, efectivamente, constituya un estilo y no la negación de todo estilo de vida). Con esto expresaba Goethe su despedida, su renuncia a un período de humanidad integral y bella que ya no volverá a darse en la historia, del mismo modo que no ha vuelto a darse otra época de florecimiento ateniense clásico» ${ }^{8}$.

Así, pues, como el propio Weber reconoce, la idea central de La ética protestante tiene contraída una gran deuda con Goethe.

Pero no acaban aquí las afinidades. En 1810 y 1817 , Goethe lee la autobiografía de Franklin, que deja una huella clara en sus Wanderjabren. Pues bien, son también las obras de Franklin (Advertencias necesarias a los que quieren ser ricos, Consejos a un joven comerciante) las que Weber toma como ejemplo del «espíritu del capitalismo», de esa «filosofía de la avaricia» cuyo ideal es el hombre honrado digno de crédito y, sobre todo, la idea de una obligación por parte del individuo frente al interés de aumentar su capital.

Las referencias a Goethe no se limitan, claro está, a La ética protestante. También aparecen en otros ensayos de sociologia de la religión y abundan en los escritos metodológicos. En cuanto a la sociología del poder, se ha señalado frecuentemente (Winckelmann, Bobbio) que los tipos puros de dominación legítima - tradicional, legal y carismática - tienen su fuente de inspiración en el pensamiento de Goethe. Este señala en los Wanderjabren tres etapas de la cultura occidental que representan tres formas simbólicas: Sitte, Vernunft, Glaube (costumbre, razón, creencia). Y en los escritos políticos los temas goethianos del daimon y del pacto con el diablo resuenan también constantemente. La política es un lugar de lucha irreconciliable entre «demonios» contrapuestos, entre diversas cosmovisiones. «El mundo está regido

${ }^{8}$ Max Weber, PE, pp. 187-188. Cito por la trad. de L. Legaz Lacambra, Barcelona, Península, 1969, pp. 257-258. 
por los demonios y quien se mete en política, es decir, quien accede a utilizar como medios el poder y la violencia, ha sellado un pacto con el diablo» ${ }^{9}$.

Pero en el contexto de la presente intervención me interesa destacar la idea de que el individuo moderno se constituye en la acción, y la afirmación de la profunda escisión del ser humano. Dos temas del Fausto que serán retomados por Weber en su concepción de la personalidad. Así, pues, la idea de individuo que, según vimos, emparentaba parcialmente a Weber con Kant, se complementa con aspectos que toma de Goethe.

En primer lugar, pienso que hay una frase en la que Fausto se define a sí mismo y que podría aplicarse también para describir la atormentada, desgarrada y contradictoria personalidad de Max Weber, que intenta llevar el dualismo y la paradoja hasta el final. En diálogo con su criado Wagner, casi al comienzo de la obra, afirma Fausto: «Dos almas residen iay! en mi pecho. Una de ellas pugna por separarse de la otra; la una, mediante órganos tenaces, se aferra al mundo en un rudo deleite amoroso; la otra se eleva violenta del polvo hacia las regiones de sublimes antepasados» ${ }^{10}$.

En segundo lugar, algunos versos más adelante, ya en su gabinete de estudio, Fausto define la modernidad por la acción del individuo. Como un nuevo Lutero se plantea traducir el evangelio de San Juan, intentando - afirma«verter con fiel sentido el original sagrado a mi amada lengua alemana».

«Escrito está: "En el principio era la Palabra”... Aquí me detengo ya perplejo. ¿Quién me ayuda a proseguir? No puedo en manera alguna dar un valor tan elevado a la palabra; debo traducir esto de otro modo si estoy bien iluminado por el Espíritu. -Escrito está: "En el principio era el sentido"... Medita bien la primera línea; que tu pluma no se precipite. ¿Es el pensamiento el que todo lo obra y crea?... Debiera estar así: "En el principio era la Fuerza"... Pero también esta vez, en tanto que esto consigno por escrito, algo me advierte ya que no me atenga a ello. El Espíritu acude en mi auxilio. De improviso veo la solución, y escribo confiado: "En el principio era la Acción"»".

Weber acepta que la principal característica del hombre moderno es la acción, y al comienzo de Economía y Sociedad define la sociología como la ciencia que pretende entender, interpretándola, la acción social, para de esta manera explicarla causalmente en su desarróllo y efectos. El hombre

${ }^{9}$ Max Weber, La política como vocación. Cito por la trad. de F. Rubio Llorente, Madrid, Alianza, 1984 (8. ${ }^{\star}$ ed.), p. 168.

${ }^{10}$ Goethe, Fausto. Cito por la trad. de J. Roviralta, en la ed. de M. J. González y M. A. Vega, Madrid, Cátedra, 1987, p. 139.

"Ibidem, pp. 141-142. Dicho sea de pasada, todas las citas del Fausto se refieren a la primera parte, pues el Fausto II es en último término hegeliano, ya que las contradicciones acaban en la superación y reconciliación. 
desarrolla su personalidad dando sentido a su acción, y en el intento de comprender dicho sentido reside el posible valor de la sociología como ciencia.

Así, pues, según mi hipótesis, la sociología de Weber surge en diálogo in los mundos de Kant y Goethe. Estos dos autores estuvieron también en (.) centro de las discusiones intelectuales de la época dorada de la Universidad de Heidelberg, a comienzos de este siglo. Hoy, que los sociólogos han olvidado ya sus orígenes filosóficos y literarios, y los filósofos también han olvidado a Goethe, la memoria de una época que no puede ser calificada de feliz pervive sólo en las bibliotecas y en la cabeza de los bibliotecarios. Pues no puede ser una mera casualidad, sino un símbolo del pasado, el hecho de que las obras de Kant y Goethe continúen estando juntas en una de las pequeñas habitaciones que forman la biblioteca del Seminario de Filosofía de la Universidad de Heidelberg. Creo que no es necesario apelar ni a Umberto Eco ni a Borges para que nos solucionen el enigma.

En lo que sigue voy a dejar en un segundo plano lo que podríamos llamar la «bipótesis goetbiana», para centrarme, si bien no exhaustivamente, en algunos elementos de la «bipótesis kantiana». En este intento de leer a Weber desde Kant voy a destacar tres elementos: en primer lugar, hablaré de la continuidad entre la filosofía kantiana y algunos conceptos clave de Max Weber, para fundamentar mi afirmación de la «sociología kantianizante». En segundo lugar, hablaré de las consecuencias de la inversión del «apotegma liberal» sobre las virtudes y los vicios o sobre el bien y el mal. Y por último, me referiré a las «afinidades electivas» entre Kant y Weber en lo que se podría llamar incoberencia liberal entre ética y modelo político.

\section{Una sociologia kantianizante}

Hace ya más de treinta y cinco años, Dieter Henrich, en su valioso estudio Die Einbeit der Wissenschaftslebre Max Webers ${ }^{12}$, señalaba que el volumen donde se recogían los ensayos de Weber sobre teoría de la ciencia contenía, junto a la metodología, sus reflexiones sobre ética. Y, además, los principios de dicha teoría de la ciencia eran, al mismo tiempo, los principios de una antropología: se trata de un concepto de hombre como ser racional, que dirige racionalmente su propia vida de acuerdo con unos principios elegidos con libertad. Henrich afirmaba las raíces kantianas tanto de la metodología como de la ética de Weber e indicaba la ironía de que los mismos ensayos que han sido leídos desde la óptica de la sociología libre de valores, contengan los elementos fundamentales de una teoría ética emparentada con Kant.

En los últimos años, la revisión de Max Weber en Alemania está sacando

${ }^{12} \mathrm{D}$. Henrich divide esta obra en dos partes, dedicadas, respectivamente, al análisis de los fundamentos de la metodología y de la ética weberianas. 
a luz, desde diversos planteamientos, las conexiones con Kant tanto en la teoría de la ciencia como en la ética. Las obras de Brugger y de Schluchter son fundamentales en esta línea interpretativa.

Schluchter insiste, en sus últimas obras, en las relaciones de Weber con el neokantismo y, por encima de éste, con la obra de Kant ${ }^{13}$. Así, por ejemplo, afirma la raíz kantiana de una de las dicotomías que recorren toda la sociología weberiana: la separación y tensión entre la búsqueda de la felicidad (riqueza, salud, larga vida, etc.); en una palabra, la acción orientada bacia el éxito, por un lado, frente a la acción orientada por valores que supone la obediencia incondicionada del individuo a valores, bien sean morales o religiosos. Es posible encontrar esta dicotomía en los escritos metodológicos (por ejemplo, en el ensayo sobre Stammler en la contraposición entre Zweckmaximen y Norm-maximen); en la teoría de la acción social (la distinción entre acción racional respecto a fines $\mathrm{y}$ acción racional respecto a valores, Zweckrationalität-Wertrationalität) $\mathrm{y}$, por consiguiente, en el análisis de los procesos de racionalización en dos esferas contrapuestas y correspondientes a las dos formas de racionalidad; en la sociologia política (la contraposición de la dominación mediante intereses y la dominación basada en la autoridad legítima); y, por fin, en la sociología de la religión (en los intentos de explicar la conducta económica de los individuos en función de los intereses propios o en función de un imperativo moral de orden religioso).

Según la tesis de Schluchter, esta dicotomía corresponde a la distinción kantiana entre imperativos hipotéticos y categóricos, distinción modelada y transformada ahora en tipologías adecuadas para la investigación histórica y sociológica ${ }^{14}$.

También la separación kantiana entre el reino de la naturaleza y el de la libertad constituye el trasfondo de la tesis weberiana de la heterogeneidad entre razón teórica y razón práctica, entre $Z$ weckrationalität o racionalidad, cuya misión consiste en elegir los medios más adecuados para lograr unos fines prefijados de antemano, y Wertrationalität o racionalidad valorativa, cuya misión radicaría en elegir ponderadamente entre diversos fines en litigio. Pues bien, en esta dicotomía repite Weber la separación kantiana entre la esfera del conocimiento racional y empírico y la esfera de la moralidad o de los valores.

Fritz Loos ha seguido paso a paso la historia de este dualismo entre ser y deber ser desde Kant a Weber pasando por Simmel, Windelband y Rickert ${ }^{15}$. No puedo entrar aquí en más detalles sobre esta separación radical entre ciencia y ética. Sólo quisiera señalar que la intención de Weber al sepa-

${ }^{13}$ W. SCHLUCHTER, Religion und Lebenstübrung, ya citado, y Gesinnungsetbik und Verantwortungsetbik. Probleme einer Unterscheidung, de próxima aparición.

${ }_{14}$ W. SCHLUCH TER, Gesinnungsetbik und Verantwortungsetbik..., p. 39 (cito por el manuscrito que amablemente me ha cedido el propio profesor Schluchter).

${ }^{15}$ Cfr. F. Loos, op. cit., pp. 36-42. 
rar la ciencia empírica y la ética normativa radica en la voluntad de «preservar la específica dignidad de cada una de ellas» ${ }^{16}$. La imposibilidad de responder científicamente a la pregunta de qué debemos hacer es la traducción weberiana de la dicotomía entre razón teórica y razón práctica postulada por Kant ${ }^{17}$. Pero esto no significa para Weber la desvalorización de la ética, sino más bien una teoria de los límites de la ciencia: la ciencia no puede crear valores, ni decidir tampoco entre ellos. No puede traspasar la barrera de la constatación de los hechos hacia la respuesta por el sentido de la vida, el valor de la cultura, o la determinación de cuál debe ser el comportamiento del individuo en la comunidad cultural o en las asociaciones políticas ${ }^{18}$. Debido al proceso de intelectualización y racionalización creciente, la ciencia no puede ser ya concebida como el camino hacia el verdadero ser de la realidad (Grecia), ni hacia el arte verdadero o la verdadera naturaleza (Renacimiento), ni tampoco hacia el verdadero Dios (como en los comienzos de la ciencia moderna influida por el protestantismo y puritanismo). Y también se muestra como una ilusión o una reliquia del pasado la concepción de la ciencia como el camino hacia la «verdadera felicidad» ${ }^{19}$.

La ciencia responde a un interés técnico diferente a las preguntas fundamentales de la razón práctica: «Todas las ciencias de la naturaleza —afirma Weber- responden a la pregunta de qué debemos hacer si queremos dominar técnicamente la vida. Las cuestiones previas de si debemos y, en el fondo, queremos conseguir este dominio y si tal dominio tiene verdaderamente sentido son dejadas de lado o, simplemente, son respondidas afirmativamente de antemano» ${ }^{20}$.

Y esta dicotomía entre ciencia y ética se resuelve también en Weber en una primacía de la razón práctica. Pues en esta dirección hay que entender las palabras de Tolstoi que Weber hace suyas en la respuesta a la pregunta por el sentido de la ciencia contemporánea: «La ciencia carece de sentido, puesto que no tiene respuesta para las únicas cuestiones que nos importan, las de qué debemos hacer y cómo debemos vivir» ${ }^{21}$.

\section{Inversión del apotegma liberal}

Es ya un lugar común de los comentaristas e intérpretes de los escritos de Kant sobre filosofía política y la filosofía de la historia, señalar el paren-

16 WEBER, WL, p. 501.

${ }^{17}$ Cfr. W' Brugger, Menschenrechtsethos und Verantwortungspolitik. Max Webers Beitrag zur Analyse und Begrïndung der Menschenrechte, Freiburg/München, Alber, 1980 , pp. $168-175$ y $309-315$.

${ }_{18}$ Cfr. Weber, WL, pp. 601-602. Cito por la ed. cast. Ciencia como vocación, Madrid, Alianza, 1984, pp. 212-213.

${ }^{19}$ Cfr. ibidem, pp. $595-598$ (ed. cast., pp. 202-207).

${ }_{20}$ Ibidem, pp. $599-600$ (ed. cast., p. 209).

21 Ibidem, p. 598 (ed. cast., p. 207). 
tesco de la «insociable sociabilidad» kantiana con el lema de Mandeville «vicios privados, beneficios públicos» o con la idea de la «mano invisible» de Adam Smith ${ }^{22}$. Ciertamente, Kant es heredero de la idea liberal según la cual el bien común o el interés de la colectividad sólo es posible a través de la búsqueda individual del propio interés o beneficio. Entre las diferentes formulaciones de esta idea en Kant, destaca la siguiente:

«Poco imaginan los hombres (en tanto que individuos e incluso como pueblos) que, al perseguir cada cual su propia intención según su parecer y a menudo en contra de los otros, siguen sin advertirlo - como un hilo conductor- la intención de la Naturaleza, que les es desconocida, y trabajan en pro de la misma, siendo así que, de conocerla, les importaría bien poco» ${ }^{23}$.

Kant generaliza el lema liberal aplicándolo en general a todos los frutos de la cultura que, según él, sólo pueden conseguirse mediante la insolidaridad, la competencia y la discordia entre los individuos. $Y$, además, lo generaliza a un segundo nivel: el de las relaciones de las naciones entre sí, de manera que el ideal de la paz perpetua y la formación de un estado cosmopolita es fruto no querido de las relaciones competitivas entre los pueblos.

$\mathrm{Me}$ interesa destacar las tres variantes de esta idea en Kant. En la variante que, a falta de mejor nombre, podemos llamar profana, la fuerza que resuelve el problema de la composición de los intereses privados en un bien colectivo se denomina Naturaleza. En la variante religiosa, dicha fuerza es la Providencia. Y en una tercera variante, la estoica, es el Destino, según la conocida máxima de Séneca: «Fata volentem ducunt, nolentem trahunt» («El Destino conduce a quien se somete y arrastra a quien se resiste») ${ }^{24}$.

Naturaleza, Providencia y Destino son identificados por el propio Kant en el suplemento sobre la garantía de la paz perpetua:

«Quien suministra esta garantía es, nada menos, que la gran artista de la naturaleza (natura daedala rerum), en cuyo curso mecánico brilla

${ }^{22}$ Esta conexión la ha señalado, por ejemplo, Habermas (Historia y crítica de la opinión pública, Barcelona, Gustavo Gili, 1981, pp. 142 y 149). Y, dentro del panorama filosófico español, han insistido en ella, entre otros, R. Rodríguez Aramayo («El "utopismo ucrónico" de la reflexión kantiana sobre la historia», estudio preliminar a KanT, Ideas para una bistoria universal en clave cosmopolita, Madrid, Tecnos, 1987, pp. XXVII y ss.), E. M. Ureña (La crítica kantiana de la sociedad y de la religión. Kant predecesor de Marx y Freud, Madrid, Tecnos, 1979, pp. 23-24) y J. Muguerza ( Un contrapunto ético: la moral ciudadana en los ochenta», en Arbor, 503-504, tomo CXXVIII, noviembrediciembre 1987, pp. 242-243).

${ }_{23}$ KanT, Idee zu einer allgemeinen Gescbicbte in weltbürgerlicben Absicbt, XI, 34. Sigo la versión castellana de C. Roldán Panadero y R. Rodríguez Aramayo (Madrid, Tecnos, 1987, p. 4).

${ }^{24} \mathrm{La}$ máxima estoica aparece tanto al final de La paz perpetua (XI, 233) como de En torno al tópico: «tal vez eso sea correcto en teoría, pero no sirve para la práctica» (XI, 172). 
visiblemente una finalidad: que a través del antagonismo de los hombres surja la armonía, incluso contra su voluntad. Por esta razón se la llama indistintamente destino, como causa necesaria de los efectos producidos según sus leyes, desconocidas para nosotros, o providencia por referencia a la finalidad del curso del mundo, como la sabiduría profunda de una causa más elevada que se guía por el fin último objetivo del género humano y que predetermina el devenir del mundo» ${ }^{25}$.

Las tres versiones tienen, a fin de cuentas, el mismo resultado: producir el bien a partir del mal, ya que hasta «el malvado moral tiene la propiedad inseparable de su naturaleza de destruirse a sí mismo y deshacer sus propios propósitos (sobre todo en relación con otros malvados), y así, aunque lentamente, abre paso al principio moral del bien» ${ }^{26}$.

De nuevo aparece aquí Goethe en mi argumentación. Pues ésta y otras formulaciones similares de Kant tienen su expresión literaria en las palabras de Mefistófeles. En efecto, la primera vez que Mefistófeles se presenta ante Fausto se define a sí mismo como «una parte de aquella fuerza que siempre quiere el mal y siempre crea el bien» ${ }^{27}$.

En Goethe, como en Kant, hasta el diablo, gracias al plan de la Providencia, acaba produciendo el bien aun en contra de su voluntad.

Me interesa la frase de Mefistófeles porque es la misma que aparece invertida en Weber. En clara referencia a Goethe -las palabras aparecen entrecomilladas - afirma en La ética protestante que el ascetismo actuaba como la fuerza «que siempre quiere el bien y siempre crea el mal» («die Kraft, die stets das Gute will und stets das Böse schaft») ${ }^{28}$. Esta es la fórmula condensada de un tema que Weber desarrollará ampliamente y que germinará en la sociología posterior ya sin referencias literarias: la paradoja de las consecuencias imprevistas -o no queridas - de la acción de los individuos, consecuencias que acaban imponiéndose sobre sus intenciones originales. De esta forma, por ejemplo, el «espíritu del capitalismo» es el fruto no querido de la predicación protestante, la burocracia que surge como servidora se convierte en dueña y señora, y el proceso de racionalización acaba conduciendo a resultados irracionales.

De las tres variantes de Kant - Naturaleza, Providencia y Destino- sólo este último pervive en Weber. Pero, claro está, en una versión mucho más desesperada, pues el destino ya no arrastra hacia el bien a quienes se le resisten, sino que el final feliz no está determinado de antemano. Las refe-

${ }^{25}$ KAnT, La paz perpetua, XI, 217. Trad. de J. Abellán, Madrid, Tecnos, 1985, p. 31.

${ }^{26}$ Ibidem, X1, 242. Expresiones similares de las relaciones entre el bien y el mal pueden encontrarse en la Antbropologie, XII, 684 y 690.

${ }_{27}$ Goethe, Faust, 1, v. 1337.

${ }^{28}$ WEBER, PE, p. 180. La misma frase invertida de Goethe, aunque en un contexto diferente, la utiliza también Weber en WL, p. 33. 
rencias al destino del individuo, de la época o de la cultura son constantes en Weber, especialmente en sus diagnósticos más personales sobre el tiempo que le tocó vivir. Pero se trata ya de un destino desencantado y secularizado en donde las referencias a la naturaleza o a la providencia han desaparecido.

Esta inversión weberiana del apotegma liberal tiene su continuación en la inversión del optimismo ilustrado. Weber convierte el optimismo de la Ilustración en un pesimismo postilustrado. Pues si Kant podía afirmar que todavía no vivía en una época ilustrada, pero sí en una época de ilustración en la que tendían a desaparecer los obstáculos para salir de la minoría de edad y utilizar la propia razón, Weber escribe al final de La ética protestante: «También parece haber muerto definitivamente la rosada mentalidad de la riente sucesora del puritanismo: la Ilustración» ${ }^{29}$. Y, sin embargo, Weber continúa siendo un ilustrado partidario del sapere aude!, transformándolo en iten el valor de elegir responsable y personalmente los valores que dan sentido a tu existencia! Los valores no son fruto de la ciencia; ni son otorgados por una divinidad providente, ni se encuentran impresos en la naturaleza del individuo, sino que éste tiene que crearlos. Dura tarea, como el mismo Weber afirma, tener que sacar los valores del propio pecho en un tiempo sin cultura subjetiva. Pero éste es el destino de nuestra época, una época que ha comido del árbol de la ciencia y donde la naturaleza y la providencia han desaparecido.

\section{Afinidades electivas en la incoherencia liberal}

En este último apartado quiero señalar una incoherencia común a todo el pensamiento liberal desde Kant hasta Rawls, pasando, claro está, por Weber. Me refiero a la doble caracterización del individuo. Cuando los liberales hablan de ética, conciben al individuo como persona moral, como un ser autónomo y libre, mientras que cuando se trata de establecer un modelo político, el individuo es conceptuado como calculador racional (Rawls), objeto de protección de la ley, pero no sujeto elaborador de ella (Kant), y mero sujeto votante y elector de un líder a cuya voluntad hay que plegarse y obedecer (Weber). En esta caracterización doble del individuo como sujeto moral y como sujeto político consiste lo que denomino la «incoherencia liberal». En lo que sigue voy a tratar de exponer las afinidades electivas entre Kant y Weber en el tratamiento de esta incoherencia que, claro está, se plantea de manera diferente en cada uno de ellos debido al cambio de las circunstancias históricas y al desarrollo del propio liberalismo. Kant es un representante del primer liberalismo alemán en lucha contra los supuestos básicos del absolutismo ilustrado. Concibe un Estado cuya tarea fundamental es la conservación de la paz y el derecho, dejando a la economía en la esfera pri-

${ }^{29}$ Weber, PE, p. 188. 
vada de la competencia de los propietarios entre sí, y defendiendo el laissez faire gracias a una concepción de la sociedad burguesa como un «orden natural», donde las fuerzas económicas dejadas a su libre competencia terminan convirtiendo los vicios privados en beneficios públicos ${ }^{30}$.

Weber, por su parte, como representante del final del liberalismo clásico, ha sido definido certeramente como un «liberal en una situación desesperada» ${ }^{31}$. Pues sigue defendiendo la causa del individualismo (no sólo económico, sino también político frente a las grandes organizaciones de masas), en una situación marcada por la intervención creciente del Estado en la economía y en la organización general de la sociedad, tras la crisis económica de 1873. Esta fecha marca el final de los sueños del primer liberalismo acerca de la separación de la economía y la política, de la sociedad civil y el Estado, de la esfera privada y la pública ${ }^{32}$.

Así, pues, comienzo y final del liberalismo clásico, pero la incoherencia entre el individuo como sujeto moral y como sujeto político permanece.

No es éste el lugar para hacer una exposición detallada de la ética de Kant. Sólo quiero destacar su concepción de la dignidad moral del individuo y su autonomía, la idea de que todo individuo ha de ser considerado como fin y nunca como medio y la postulación de un «reino de los fines» donde todos los sujetos morales son colegisladores. Pues bien, el paso de la ética a la construcción de un modelo político podría definirse para una mayoría de la población como el paso de la autonomía a la dependencia: el «Reino de los fines» parece no ser de este mundo y, quizá por ello, adopta Kant criterios mucho más restrictivos cuando habla de la República terrenal. En efecto, aquí ya no son colegisladores todos los individuos, sino única y exclusivamente la élite de los propietarios.

En Über den Gemeinspruch..., Kant diseña un modelo político basado en los principios de la libertad de cada miembro de la sociedad en cuanto hombre, la igualdad de todos en cuanto súbditos y la independencia de cada miembro de la comunidad en cuanto ciudadano, es decir, colegislador. Todos los individuos son libres e iguales, pero no todos son ciudadanos, es decir, no todos son iguales en cuanto al derecho de acceso al raciocinio político, al sufragio y al derecho de colaborar en la elaboración de las leyes. En este sentido afirma Kant:

${ }^{30}$ Véase el análisis de F. GonzÁlez VICÉN, «La filosofía del Estado en Kant», recogido ahora como primer capítulo de su libro De Kant a Marx (Estudios de bistoria de las ideas), Valencia, F. Torres, 1984.

${ }^{31}$ Cfr. la caracterización que Mommsen hace de Weber en Max Weber: Gesellschaft, Politik und Gescbichte, Frankfurt, Suhrkamp, 1974 (hay trad. de E. Garzón Valdés en la Edit. Alfa). Véase especialmente el primer capítulo, titulado «Ein Liberaler in der Grenzsituation». Véase, también, el libro de MommSEN, The Age of Bureaucracy. Perspectives on the Political Sociology of Max Weber, Oxford, Blackwell, 1974.

${ }_{32}$ Cfr. los caps. IV y V de J. Habermas, Strukturwandel der Oeffentlicbkeit, Darmstad-Neuwied, Luchterhand, 1962 (hay trad. de A. Domènech con el título Historia y critica de la opinión pública, Barcelona, Gustavo Gili, 1981). 
«Ahora bien: aquel que tiene derecho a voto en esta legislación se llama ciudadano (citoyen, esto es, ciudadano del Estado, no ciudadano de la ciudad, bourgeois). La única cualidad exigida para ello, aparte de la cualidad natural (no ser niño ni mujer), es ésta: que uno sea su propio señor (sui iuris) y, por tanto, que tenga alguna propiedad (incluyendo en este concepto toda habilidad, oficio, arte o ciencia) que le mantenga; es decir, que en los casos en que haya de ganarse la vida gracias a otros lo haga sólo por venta de lo que es suyo, no por consentir que otros utilicen sus fuerzas; en consecuencia, se exige que no esté al servicio - en el sentido estricto de la palabra - de nadie más que de la comunidad. En este orden de cosas los pertenecientes al artesanado y los grandes o pequeños propietarios son todos iguales entre sí, a saber, cada uno sólo tiene derecho a un voto» ${ }^{33}$.

Obsérvese que para el acceso a la categoría de ciudadano hay dos tipos de limitaciones: unas, definidas como sociales o económicas - ser propietario-, y otras, definidas como naturales: no ser mujer o niño. Aun en el supuesto de que se cumpliese la idea liberal de igualdad de oportunidades en el acceso a la propiedad, y todos los varones pudieran ser ciudadanos, siempre quedaría la otra limitación, llamada natural, que deja fuera del derecho de ciudadanía a las mujeres. Pues si bien los niños podrían atravesar la barrera natural al hacerse adultos, las niñas y las mujeres estarían condenadas a ser mero objeto de protección de la ley y nunca sujeto elaborador de ella.

El propio Kant reconoce las dificultades para determinar con precisión en algunos casos quién es propietario de sí mismo («es algo difícil, lo confieso, determinar los requisitos que ha de satisfacer quien pretenda la posición de un hombre que sea su propio señor»), pero, como señala Habermas, «llega, sin embargo, a una adecuada delimitación frente a lo que más tarde se llamará libre trabajo asalariado» ${ }^{34}$. El trabajador por cuenta ajena, aquel que tiene como única propiedad su trabajo, queda excluido de la categoría de ciudadano.

Cuatro años más tarde, en 1797 , la distinción entre «ciudadano» y «coprotegido» se transforma ligeramente, pero la idea de fondo permanece. En la Metafísica de las costumbres, al hablar del derecho de ciudadanía, Kant distingue entre ciudadanos activos y pasivos. $\mathrm{Y}$ sólo los primeros, es decir, los propietarios y los funcionarios del Estado, tienen personalidad civil y por lo tanto derecho de sufragio. En último término, sólo ellos pueden ser considerados propiamente ciudadanos (Staatsbürger) y no meros «asocia-

${ }^{33}$ Kant, Úber den Gemeinspruch..., XI, 151. Sigo la trad. de R. Rodríguez Aramayo en Kant, Teoría y práctica, Madrid, Tecnos, 1986, pp. 34-35.

${ }^{34}$ Habermas, op. cit., versión castellana, p. 143. 
dos civiles» (Staatsgenossen) ${ }^{35}$. Todo el que trabaja para otro que no sea el Estado y no es propietario más que de su fuerza de trabajo debe ser mandado y protegido por otro individuo, no goza de independencia civil, no tiene derecho de sufragio y no puede contribuir a la discusión y elaboración de las leyes; carece de personalidad civil y su existencia no es más que un accesorio de la de otro. Estas expresiones, que son del propio Kant, están muy lejos de la autonomía y la universalidad del sujeto moral; quien cuenta en política* es el propietario y la idea de individuo se transforma en algo bastante parecido al «individualismo posesivo», en la conocida acepción que Macpherson hace del término ${ }^{36}$.

Este modelo de sufragio censitario y ciudadanía limitada, versión ilustrada del modelo griego, va a ser ampliado en el proceso histórico. La extensión del derecho de sufragio es fruto, entre otros factores, de la articulación política de la clase obrera, de la irrupción de las masas en la política y de la lucha feminista. Weber, al final del período clásico del liberalismo alemán, construye un modelo político democrático basado en el sufragio universal. En su teoría se vislumbran ya los problemas de la personalización del poder, la transformación de la opinión pública en objeto de la propaganda electotoral y del marketing político, y el peso de la maquinaria de los partidos, problemas que alcanzarán su pleno desarrollo con las democracias de masas posteriores a la segunda guerra mundial.

No pretendo tanto comparar la ética (desarrollada) de Kant con la ética (en ciernes, en gran medida) de Weber, cuanto comparar el esquema de pensamiento y la «incoherencia liberal» entre una ética de la autonomía de todos y cada uno de los individuos y un modelo político que niega tal autonomía generalizada, reservándola a unos pocos: el modelo ilustrado de sufragio censitario en Kant y la «democracia plebiscitaria del líder» en Weber.

Tal vez influido por Simmel y por sus discusiones con él sobre Goethe y Kant, desarrolla Max Weber una idea del individualismo ético llevada hasta el final ${ }^{37}$. El núcleo básico de esta teoría radica en la exigencia hecha al

${ }^{35}$ Kant, Die Metaphysik der Sitten, VIII, 432-433.

${ }^{36}$ Cfr. Macpherson, The Political Theory of Possesive Individualism, Oxford University Press, 1962. Hay trad. de J. R. Capella, Barcelona, Fontanella, 1970.

${ }_{37}$ Doy por conocidas las relaciones de amistad entre Max Weber y Simmel y la influencia de éste sobre aquél, señalada frecuentemente en torno a la recepción de Nietzsche. Se suele recordar que Weber leyó y anotó cuidadosamente el libro de Simmel sobre Schopenhauer und Nietzsche. Lo que ya no está tan estudiado es la influencia de Simmel en la recepción de Kant y Goethe. A comienzos de siglo, Simmel dedica varias monografías y artículos a estos dos autores, conjuntamente (Kant und Goethe, Berlín, Marquardt, 1906) y por separado. Sobre Kant puede verse su Kant. 16 Vorlesungen gebalten an der Berliner Universität, Dritte, erweitere Auflage, München-Leipzig, 1913. Y sobre Goethe, los artículos "Die Wahrheit und das Individuum. Aus einem Goethe Buch" (Logos, 3, 1912, pp. 15-28), "Goethes Individualismus" (Logos, 3, 1912, pp. 251-274) y, especialmente, su libro Goetbe, dedicado, por cierto, a Marianne, la mujer de Max Weber (Leipzig, Klinkhardt und Biermann, 1913). La discusión de la ética kantiana puede verse también en su artículo «Das individuelle Gesetz. Ein Versuch über das Prinzip der Ethik» (Logos, IV, 1913, pp. 117-160). En el presente contexto, lo que podríamos llamar la 
individuo - a todos y cada uno de los individuos- para que se desarrolle como persona, mediante la dirección consciente de su propia vida basada en la elección libre, autónoma y responsable de los valores últimos que la guían y dan sentido.

Dieter Henrich ha resumido la ética de Weber, contenida en la Wissenscbaftslebre, con las siguientes palabras:

«La consciente orientación valorativa es la esencia de la personalidad $y$, por tanto, el fin del ser humano. La realización de la esencia del hombre es la más alta tarea ética. Así, pues, el primer imperativo de la moral es el siguiente: intenta llegar a ser persona (Persönnlicbkeit), consigue claridad sobre los significados de tu acción y permanece fiel a ti mismo cuando hayas elegido un ideal razonable (ein vernünttiges Ideal), actuando consecuentemente con lo elegido» ${ }^{38}$.

Los valores no pueden ser producto de la ciencia, ni están inscritos en la naturaleza humana, ni son revelados por una divinidad, ni son decididos por esa especial versión de la divinidad que, según los lamas tibetanos, traídos a colación por Kant en una nota de La paz perpetua, equivale a la reunión o comunión de los santos (Versammlung aller Heiligen) ${ }^{39}$.

Sólo queda el individuo, abandonado a sus propias fuerzas. «Libertad de elección, obligación de elegir, dicho brevemente: autodeterminación, es el lema decisivo de Weber. $\mathrm{Y}$ esta autodeterminación debe ser consciente $\mathrm{y}$, por tanto, ilustrada» ${ }^{40}$.

Como elementos de ilustración pueden ser útiles la filosofía (que en este sentido puede ir más lejos que la ciencia) y el diálogo racional sobre los valores ${ }^{41}$. Y, sin embargo, un resto decisionista es insalvable. La ciencia, la filosofía o el diálogo racional pueden ayudar a esclarecer la decisión, pero no pueden suplantarla.

No puedo exponer aquí con más detalle la postura ética de Weber: sólo quiero señalar que no es partidario de un decisionismo ciego e irracional en las cuestiones morales (aunque un resto decisionista es insalvable), ni tampoco defiende un relativismo radical en el que da lo mismo elegir un valor u otro. El pluralismo valorativo y la Wertkollision no tienen que confundirse con el relativismo. Y, por otro lado, cabría entender toda su sociología de la religión como una inmensa contribución a un diálogo entre los

bipótesis Simmel (es decir, la influencia de Simmel en Weber) confluye, en último término, en las otras dos ya señaladas: la bipótesis Kant y la bipótesis Goethe. Un estudio más detallado de las relaciones intelectuales entre los dos sociólogos excede los límites de este artículo.

${ }^{38}$ D. HENRICH, op. cit., p. 113.

${ }^{39}$ KaNT, Zum ewigen Frieden, XI, 215.

${ }^{40} \mathrm{~W}$. SCH LUCH TER, Gesinnungsetbik und Verantwortungsethik..., op. cit., p. 104.

${ }^{41}$ Cfr. WeBER, WL, pp. 507-508. 
valores de las distintas religiones y culturas, diálogo que puede ayudar al individuo a elegir el sentido de su vida, desarrollando su personalidad, como antes he indicado. Pero este diálogo no termina en ningún tipo de consenso como los postulados por la ética contemporánea, sino en el disenso, en el politeísmo de los valores (Polytbeismus der Werte) y en la colisión entre los dioses y demonios que pueblan el campo de la razón práctica, pues «los distintos sistemas de valores existentes libran entre sí una batalla sin solución posible» ${ }^{42}$.

Así, pues, como señala Schluchter, la discusión sobre los valores tampoco es una instancia superior que decida sobre las luchas de los dioses (Kampf der Götter) ${ }^{43}$. Es sólo una instancia que puede contribuir a hacer más racional la elección, pero ni puede suplantar la decisión de los individuos, ni puede tampoco conseguir un compromiso definitivo que apacigüe a los dioses. «La vida es trágica en un determinado sentido, tanto en el encantado mundo griego como en el desencantado mundo moderno. No es tanto el sentimiento del escepticismo, sino más bien el de la tragedia, el que atraviesa toda la obra de Weber» ${ }^{44}$.

En cuanto al modelo político, creo que hay que destacar la lucha apasionada de Weber, al menos desde 1906, por la parlamentarización real de Alemania frente al régimen autocrático y semiconstitucional de Guillermo II. En este sentido, sus artículos políticos obtuvieron una gran resonancia durante la primera guerra mundial. La defensa del Parlamento frente al poder del monarca y, especialmente, de la burocracia, está acompañada por el intento de la integración de la clase obrera en el sistema político a través de una extensión del derecho de voto a toda la población. $\mathrm{Y}$, sin embargo, «la idea del antiguo liberalismo, en el sentido de una élite de personalidades económica y socialmente independientes, a diferencia del "ciego" dominio del principio de la mayoría es la más adecuada para hablar en representación de toda la nación, encuentra su continuación en el pensamiento de Max Weber» ${ }^{45}$.

La idea del liderazgo obtiene un protagonismo importante en el modelo: los partidos políticos asumen el papel de organizar, canalizar y crear las demandas de un electorado fundamentalmente pasivo. $\mathrm{Y}$ los partidos, para ser eficaces en la lucha por los votos, generan una estructura férrea en torno a un líder que tiene éxito en la venta de su propia imagen. La democracia se convierte en un sistema de selección de líderes.

Como he señalado en otro lugar ${ }^{46}$, Weber da dos soluciones, históricamente sucesivas, a la cuestión del procedimiento de selección del líder polí-

${ }_{42}$ WeBER, WL, pp. 603 y 604.

${ }^{43}$ Cfr. Sch luch Ter, ibidem, p. 129.

${ }^{44}$ Ibidem, p. 130.

${ }^{45}$ W. Mommsen, Max Weber: sociedad, politica e bistoria, ed. cit., p. 52.

${ }^{40}$ Véase el primer apartado de mi artículo «Crítica de la teoría económica de la democracia», en el libro, editado por F. Quesada y por mí, Teorías de la democracia, Barcelona, Anthropos, 1988. 
tico. Primero, al abogar en 1917 por la parlamentarización de Alemania, defiende la importancia del Parlamento como lugar de selección de líderes a través de la lucha política. Pero más tarde, decepcionado de la actividad parlamentaria, propugna la elección presidencial directa a través de la participación popular.

En esta «democracia plebiscitaria del líder» (plebiszitäre Fübrerdemokratie), basada en el líder y en la maquinaria de los partidos, ya no cabe aquella posible extensión del concepto de personalidad (Persönlichkeitsbegriff) a todos y cada uno de los ciudadanos. Más bien, parece que lo único que le queda al común de los mortales es elegir al líder (que sí puede ser una personalidad en el sentido weberiano) y obedecer, plegándose a su voluntad.

De nuevo aquí llegamos a una solución política elitista en incoherencia con planteamientos éticos que tenían pretensión de universalidad. Pero tal vez sea ésta una inconsecuencia común a todo el pensamiento liberal que nosotros, como herederos de dicho pensamiento, seguimos sin resolver.

Quisiera terminar con una cita de! final de Wissenscbaft als Beruf. Allí señalaba Weber que la honestidad intelectual le hacía constatar que la situación de todos los que en aquel invierno de 1918-19 esperaban nuevos profetas y salvadores, era la misma que resonaba en la canción del centinela edomita, de la época del exilio, recogida en las profecías de Isaías:

«Una voz me llega de Seir, en Edom:

"Centinela, ¿cuánto durará la noche aún?"

El centinela responde:

"La mañana ha de venir, pero es noche aún.

Si queréis preguntar, volved otra vez".»

«El pueblo a quien esto fue dicho ha preguntado y esperado durante más de dos mil años y todos conocemos su estremecedor destino. Saquemos de este ejemplo la lección de que no basta con esperar y anhelar. Hay que hacer algo más. Hay que ponerse al trabajo y responder, como hombre y como profesional, a las "exigencias de cada día". Esto es simple y sencillo si cada cual encuentra el demonio que maneja los hilos de su vida y le presta obediencia» ${ }^{47}$.

Todo el final de la conferencia de Weber está lleno de referencias al destino, a ese destino al que se reducía la herencia de Kant cuando desaparecían la providencia y la naturaleza. Por otro lado, en el texto que acabo de citar aparece entrecomillada una referencia a Goethe: «las exigencias de cada día» (die Forderung des Tages). Se trata de una especie de leit-motiv que, al igual que otras referencias goethianas, Weber repite en diferentes p. 231 .

47 Weber, WL, p. 613. Cito por la trad. cast. de La ciencia como vocación, ed. cit., 
$\operatorname{contextos}^{48}$, dando por supuesto que el lector conoce el contenido de la máxima aludida. Y, a pesar de que Goethe afirmase que carecía de un sentido especial para la filosofía, hay que entender dicha máxima a la luz del pensamiento del viejo de Königsberg, que es como el propio Goethe llamaba a Kant. Acción, deber y conocimiento de uno mismo se encadenan en la reflexión de Goethe, que, entera, rezaría así:

"¿Cómo puede uno conocerse a sí mismo? Nunca mediante la introspección, sino más bien a través de la acción. Intenta cumplir con tu deber e inmediatamente sabrás qué es lo que hay en ti.

Pero ¿cuál es tu deber? Las exigencias de cada día (die Forderung des Tages)》 ${ }^{49}$.

\section{ABREVIATURAS}

- Max Weber

PE: Die protestantiscbe Etbik, edición de J. Winckelmann en 2 vols., Freiburg, Gütersloher, 1984 (7.. ed.).

WL: Gesammelte Aufsätze zur Wissenschaftslebre, 6. ${ }^{\mathrm{a}}$ ed. a cargo de J. Winckelmann, Tübingen, J. C. B. Mohr, 1985.

- Para las obras de Kant utilizo la edición de W. Weischedel en 12 vols., Frankfurt, Suhrkamp, 1977. La primera cifra, en romanos, corresponde al volumen, y la segun. $\mathrm{da}$, a la página.

${ }^{48}$ Así, en WL, pp. 494 y 613; Gesammelte Politische Scbriften (editados por J. Winckelmann, 2." ed., Tübingen, Mohr, 1958), pp. 145, 286, 295 y 330, y en Gesammelte Aufsätze zur Religionssoziologie, vol. II, Tübingen, Mohr, 1963, 3. ed., pp. 193-194. Sobre este tema, véase el libro ya citado de Brugger, pp. 270-271.

"4 GoETHE, Aforismos 2 y 3 de «Betrachtungen im Sinne der Wanderer», en Sprüche, vol. 6 de la edición de Insel Verlag, p. 451. 